\title{
Simulating the Sustainability of Xiong'an New Area Undertaking the Industrial Transfer from Beijing
}

\author{
Fangqu Niu (iD) ${ }^{1,2}$ \\ ${ }^{1}$ Key Laboratory of Regional Sustainable Development Modeling, \\ Institute of Geographic Sciences and Natural Resources Research, Chinese Academy of Sciences, Beijing 100101, China \\ ${ }^{2}$ Collaborative Innovation Center for Geopolitical Setting of Southwest China and Borderland Development, \\ Yunnan Normal University, Kunming 650500, China \\ Correspondence should be addressed to Fangqu Niu; niufq@lreis.ac.cn
}

Received 10 March 2021; Revised 15 April 2021; Accepted 3 May 2021; Published 17 May 2021

Academic Editor: Jing-Hu Pan

Copyright $\odot 2021$ Fangqu Niu. This is an open access article distributed under the Creative Commons Attribution License, which permits unrestricted use, distribution, and reproduction in any medium, provided the original work is properly cited.

\begin{abstract}
The national new area Xiong'an has been established to take over the noncapital functions of Beijing in China. In light of local resources and environmental constraints, it is important to clarify the mode of industrial transfer for Xiong'an new area (XNA) to achieve the developmental goals. This study simulates and analyzes the speed of industrial transfer and the capacities of XNA in light of resource and environmental constraints. The results show that, to just realize modernization in 2035, the transfer rate of the secondary industry and tertiary industry is annually 3.7 billion yuan and 6.4 billion yuan, respectively. But at this speed, the atmospheric environment will be overloaded by 2028. The minimum and maximum transfer rate to realize modernization in 2035 without overloading resources and environment are also specified as well as the total size of economy and population. The results indicate that land for the construction of XNA is rich, but local water is not sufficient to support industrial growth. The atmospheric environment of XNA is also an important limiting factor. It is thus necessary to reduce air pollution and increase the population and industrial scale of the area by increasing the transfer rate of the tertiary industry.
\end{abstract}

\section{Introduction}

The population and scale of large cities are constantly increasing with the economic development and urbanization. Urban space is rapidly expanding outward, leading to a series of problems, such as improper land use, traffic congestion, and environmental pollution [1]. In this case, new areas emerge and break the sprawl in the city [2-4]. These peripheral areas take on part of the functions of the central city and have frequent and intensive contact with the entire city at the same time [5]. The construction of new areas is usually carried out with a clear direction for development and special supporting policies and has become an important means for the government to promote regional economic development.

In April 2017, the Central Committee of the Communist Party of China proposed establishing the Xiong'an new area (XNA), Hebei Province. The establishment of the XNA is an important measure to implement the strategy of the coordinated development of the Beijing-Tianjin-Hebei region and to move over the noncore functions of Beijing as the capital. The aim is to convert XNA into a green, low-carbon, competitive, and influential modern city by 2035 . On the contrary, China's rapid economic growth in the past 40 years, since the reform and opening-up in 1978, has led to a series of serious imbalances and disharmony [6]. They are prominently manifested in the excessive consumption of resources and increased environmental pollution. The rapid expansion of the capital, Beijing, as one of China's megacities, has led to congestion and pollution. The establishment of the XNA is highly targeted, and it is necessary to draw lessons from the past in order to maintain high-quality development.

Therefore, in light of limited resources and environmental constraints, the government and researchers are faced with the following questions to achieve the 
development goals: what kind of mode of industrial transfer should be chosen, what should the expected speed of industrial transfer be, and what population and economic scale should be adopted for XNA?

\section{Literature Review}

Research on new areas can be traced back to the garden city proposed by the British urbanologist Ebenezer Howard at the end of the 19th century [7] to resettle the population outside big cities, set up hospitals, industries, and cultural, recreation, and commercial centers, and form a new and relatively independent society. He advocated for the establishment of new cities to solve urban problems, and this has had an important impact on the subsequent construction of satellite cities and research on urban function dispersion theory. Since the 1990s, with the emergence of suburbanization and counterurbanization, low-carbon space [8], fringe cities [9], and smart growth [10] have become major issues of research on new areas, and more attention has been paid to the emergence of urban problems and coordinated regional development in the context of urban sprawl and expansion. The new area is considered an important carrier of urban spatial growth that can share functions of the central city, thus providing an important means to redistribute urban population and realize industrial transfer [11]. The focus of the research has gradually shifted from the social and economic needs of the new area to its ecological needs.

In general, different from Western countries, where new areas are mainly decentralized, China's new areas are planned and designed at the national level under the leadership of the government, with the aim of developing them into poles of regional economic growth [12]. Therefore, the construction and development of China's new areas have distinctive characteristics. Research on new areas in China began in the 1990s. In this period, the scale of cities expanded rapidly, and "big city disease" became more and more serious. This made it increasingly important to study the distribution of urban functions. Studies on the relevant functions have been carried out from the two perspectives of population and industry. Xie [13] analyzed the plane and vertical modes of population evacuation in megacities, which caused researchers to attend to population evacuation. Taking Shanghai and Changsha as examples, Shi and Liu [14] and $\mathrm{Xu}[15]$ analyzed the characteristics of the urban industrial layout and proposed measures to optimize the industrial distribution in downtown areas. Meng [16] studied the layout of the commercial medical industry in Beijing with the help of GIS technology and proposed that medical resources in Dongcheng and Xicheng districts are distributed externally to reduce congestion. On this basis, other scholars have claimed that land price, labor cost, transportation factors, and government guidance are the main driving forces for the migration of the population and industry to the outskirts of cities [17-20]. They have also proposed that industrial relocation can drive population relocation [21,22]. With the successive establishment of new areas at the national and regional levels, the academic circle has begun conducting more and more empirical studies on their planning and construction.

The research has focused on three perspectives: (1) Strategic positioning and functions of new areas. New areas at different scales often have diversified functional positioning, including regional open doors, economic growth poles, and inland open economic highlands [23, 24]. (2) Spatial pattern and management system. The research has focused on the location selection and spatial pattern of the new area [25-28], and scholars have explored management systems for it [29]. (3) Relations between new and old urban areas. This is mainly the problem of industrial transfer and production-city integration in old and new urban areas [30,31]. The literature has not only analyzed the developmental path and problems of individual new areas [32] but also compared the functions and advantages of several new areas [33] to understand the relationships of heterogeneity and coopetition relationship among them. The aim is to determine the driving mechanisms for the development of different new areas and their effects on the regional economy.

It could be concluded that few dynamic simulations and predictions of the impact of industrial transfer on economic development are available concerning the resource and environment carrying capacity. This study simulates and analyzes the industrial transfer from Beijing to XNA and determines the appropriate speed of this transfer and the maximum scale of it under different modes. Through a comparison of scenarios, the appropriate plan is determined to provide decision-making support for realizing the sustainable development of XNA. This study contributes to work on new areas in terms of models of industrial undertaking. It is also a response to the framework document of "Future Earth" initiative.

\section{Study Area and Data}

Based on the specific needs for economic and social development at various stages, China (as of March 2019) has established 19 state-level new areas, 7 special economic zones, and 12 free trade zones since the establishment of the Shenzhen special economic zone in 1980. Although various zones have different names, they are all subject to special policies and thus are collectively called "new areas." Of them, state-level new areas are established with the approval of the State Council of China. Based on the relevant administrative regions and special functional zones, they undertake the major tasks of national development and the reform and opening-up strategy [34]. They have the general characteristics of new space, new function, and new mode, different from those of the old city. This highlights the strategic direction of the country and the unique characteristics of "strategy and leading" [35]. The spatiotemporal distribution of state-level new areas is shown in Figure 1.

XNA is located in Hebei Province and includes the three counties of Xiongxian, Rongcheng, and Anxin as well as part of the surrounding areas (Figure 2). It covers an area of 1770 $\mathrm{km}^{2}$. According to the Hebei Economic Yearbook 2018, the population of the area in 2017 was 1.109 million and its GDP was 2.77 billion USD. The multiyear average volume of water 


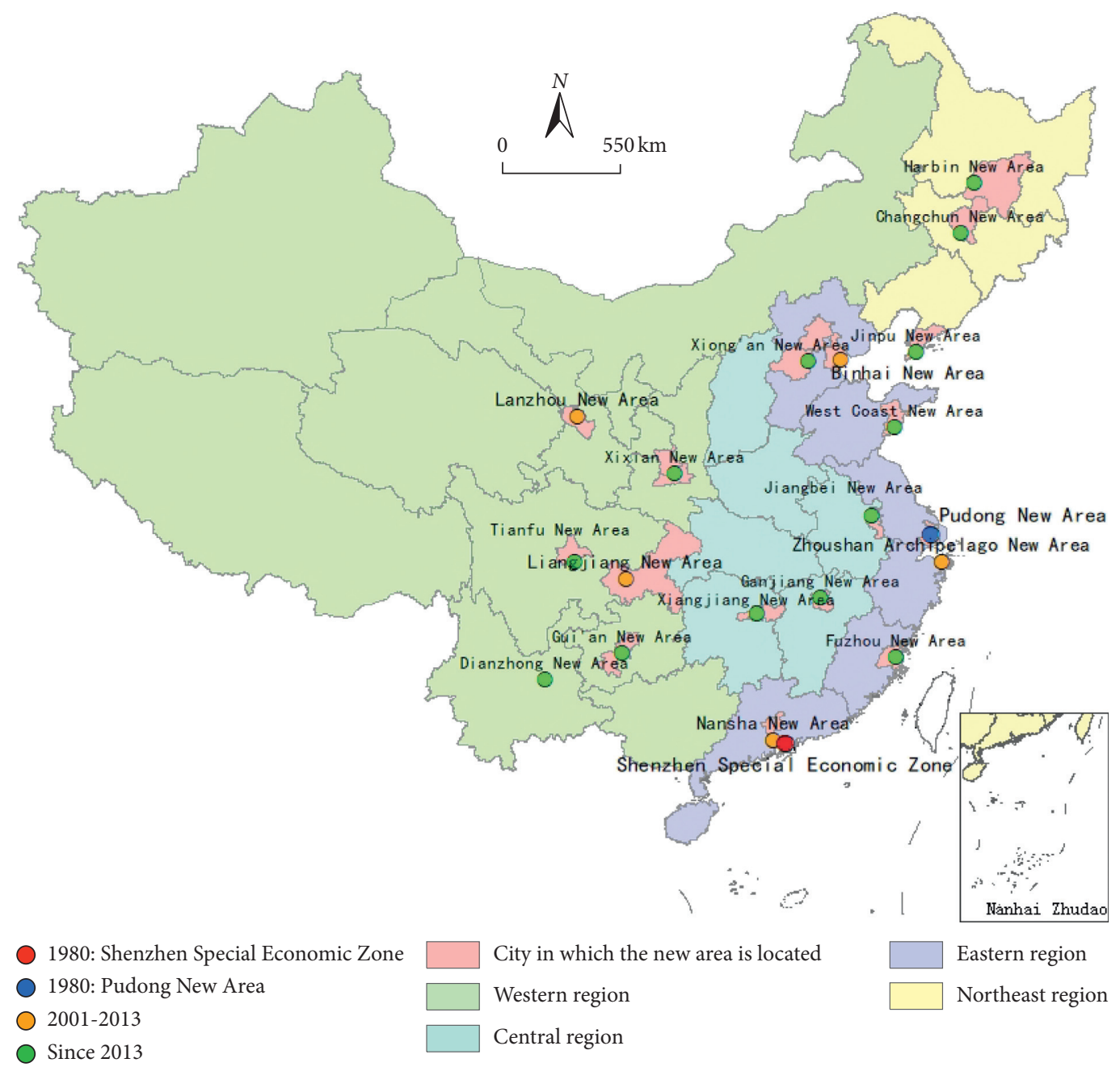

FIGURE 1: Spatiotemporal distribution of China's new area.

resources of XNA was 173 million cubic meters [36]. According to its developmental location, it will undertake the capital's emerging industries as well as its science and education industries and establish an ecologically livable and innovative leading zone. The region covers approximately $2000 \mathrm{~km}^{2}$. The long-term plan is for the area to have a population of 2 to 2.5 million.

The data were drawn from various statistical yearbooks, including Hebei Economic Yearbook (2018), Beijing Statistical Yearbook (2018), and Statistical Yearbook of Urban Construction in China (2017). The data source for each index is explained below in the corresponding section.

\section{Methodology}

In the process of regional socioeconomic development, the interaction of such factors as the industry, population, resources, and the environment forms a complex dynamic system. Changes in each factor affect other factors. The system dynamics model is suitable for simulating the process of change in nonlinear systems $[37,38]$ and has been widely used in simulations of the relationship between the social economy and the resource environment $[7,39]$. This paper constructs a system dynamics model called the Xiong' an Model (XAM) to simulate the industrial structure and scale, population scale, changes in urbanization as well as its impact on the water and atmospheric environment, and the consumption of land and water resources in XNA during the industrial transfer from Beijing. In this way, XAM helps determine suitable speeds for the industrial transfer and the upper limits of scale under different industrial transfer modes to achieve the goals set out for it by the government.

XAM includes an industrial module, a population module, an urbanization module, an environmental capacity module, a land demand module, and a water demand module. Using the available data and planning targets for XNA, with 2017 as the base year, a year-by-year simulation of XNA is conducted until 2035. Vensim DSS was used as a development platform.

4.1. Industry and Population Modules. People go where the industry is, because of which the population and industry modules considered here are intimately linked. The transfer 


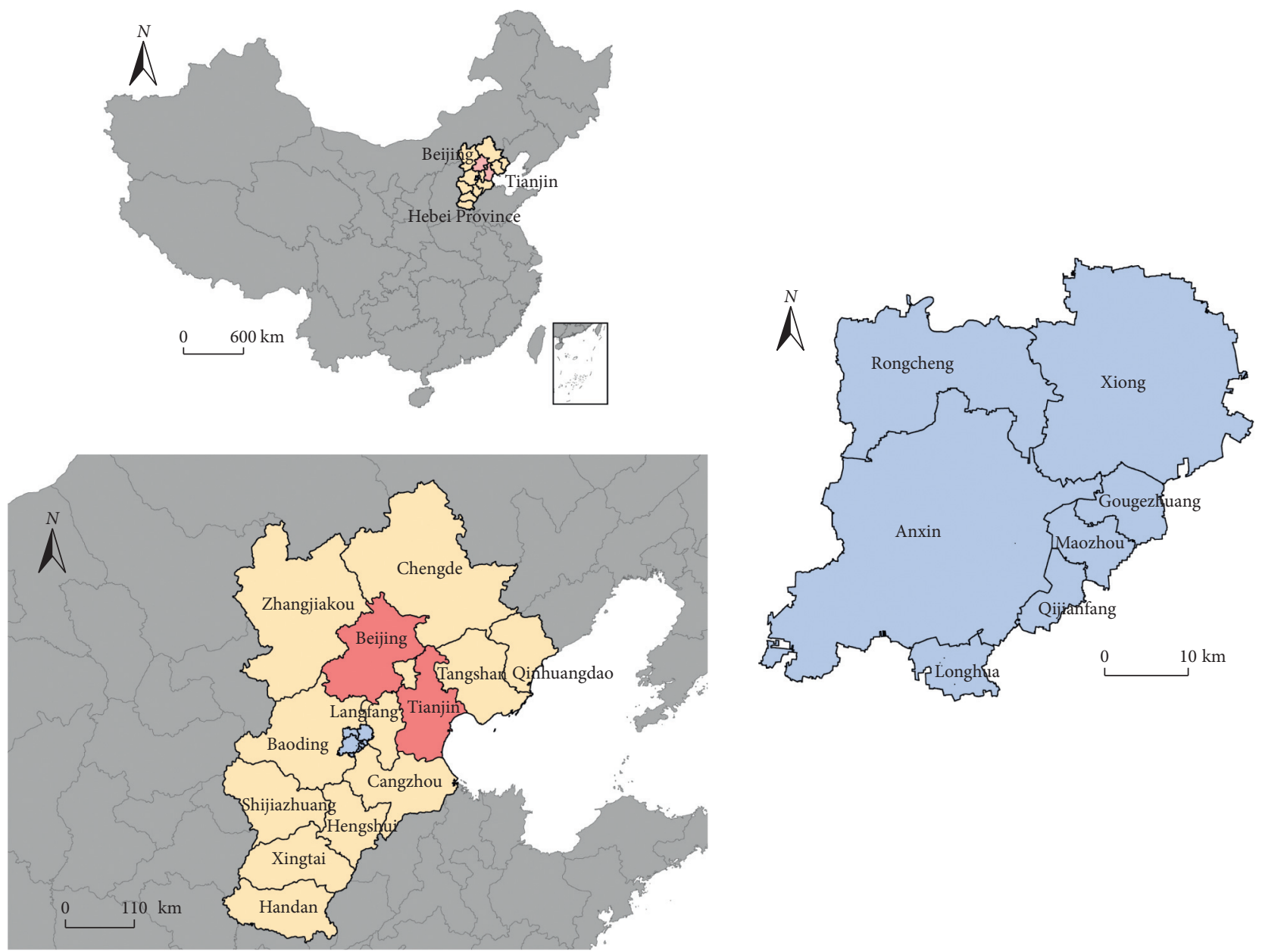

FIgure 2: Study area: Xiong'an, China.

of Beijing's industries to XNA will inevitably be accompanied by population migration. We calculate the population corresponding to the transferred industries based on the number of employees in each.

By the end of 2017, Beijing had a permanent population of 21.71 million, with 12.47 million employees, including 488,000 in the primary industry, 1.93 million in the secondary industry, and 10.05 million in the tertiary industry. The ratio of the permanent population to the number of employees was $1.74: 1$, so the populations corresponding to the above three industries were thus 0.85 million, 3.35 million, and 17.49 million people, respectively. The GDP values of Beijing's primary, secondary, and tertiary industries in 2017 were 12.04 billion, 532.68 billion, and 2256.78 billion yuan, respectively, and their per capita GDP values were 14,200 yuan/person, 158,800 yuan/person, and 129,900 yuan/person, respectively. It is reasonable to assume that the same industry corresponds to the same number of employees under the same technical level no matter wherever they are located.

Based on the scale of the transferred industries and per capita GDP, the population corresponding to the transferred industries can be calculated. The migrant population plus the local population is the total population:

$$
\begin{gathered}
\operatorname{pop}_{n}=\frac{\mathrm{GDP}_{s}}{15.88}+\frac{\mathrm{GDP}_{t}}{12.90}, \\
\text { pop }=\operatorname{pop}_{l}+\operatorname{pop}_{n} .
\end{gathered}
$$

In the above, $p o p_{n}$ is the total population corresponding to the transferred industries, $G D P_{s}$ and $G D P_{t}$ are the transfer scales of the second and tertiary industries, respectively, and $p o p$ and $p o p_{l}$ are the total population and local population, respectively. The population of XNA will continue to grow with industrial transfer. The variables that we need to determine are the speed of industrial transfer, its scale, and the corresponding total population.

4.2. Urbanization Module. According to the Hebei Economic Yearbook 2018, the rate of urbanization of XNA in 2017 was $45.23 \%$ and its urban population was 501,600 . The population transferred for the secondary and tertiary industries was regarded as the urban population, and that corresponding to the local original industry was added to obtain the total urban population, as shown in equation (2).

$$
\text { UrbanRatio }=\frac{\text { pop }_{\text {localurban }}+\text { pop }_{n}}{\text { ttlPop }} .
$$


In the above, UrbanRatio is the urbanization rate, poplocalurban is the orginal local urban population, ${ } o p_{n}$ is the urban population corresponding to the transferred industry, and $t$ tlPop is the total population. The population parameter is obtained from the output of the population module.

4.3. Water Demand Module. According to the Beijing Statistical Yearbook 2018, the city's per capita GDP is 129,000 yuan. The total water consumption was 3.95 billion cubic meters, of which the first industry used 510 million cubic meters at an intensity of water use of $423.24 \mathrm{~m}^{3} / 10,000$ yuan. The secondary industry used 350 million cubic meters at an intensity of $6.59 \mathrm{~m}^{3} / 10,000$ yuan; domestic water consumption was 1.83 billion $\mathrm{m}^{3}$ (including water used by the tertiary industries) at an intensity of $84.31 \mathrm{~m}^{3}$ per person; in addition, the ecological water consumption was 1.26 billion $\mathrm{m}^{3}$, accounting for $31.9 \%$ of the total. Given the same technical level, we assume that the intensity of industrial water use remains the same.

A region with water consumption exceeding $70 \%$ of the total local water resources is usually regarded as suffering from severe water shortage $[40,41]$. Therefore, we set $70 \%$ of the water resources as the upper limit of water use. The total available water resource in XNA was 156 million cubic meters, and the usable volume was 109 million $\mathrm{m}^{3}$. If the total amount of water used for production and domestic use as well as ecological water exceeded this value, a serious water shortage was considered to have occurred. The total water consumption was calculated as

$$
\begin{aligned}
w= & \mathrm{GDP} * r_{\mathrm{pri}} * 423.24+\mathrm{GDP} * r_{\mathrm{sec}} * 0.026 \\
& + \text { pop } * 0.006+w_{\mathrm{eco}},
\end{aligned}
$$

where $w$ is the total water consumption, $r_{p r i}$ and $r_{s e c}$ are the ratios of the primary and secondary industries, respectively, pop is the population, and $w_{\text {eco }}$ is the ecological water use. The values $423.24,0.026$, and 0.006 represent the intensities of use of the primary and secondary industries and those of domestic water use, respectively.

4.4. Water Environment Capacity Module. The quality of the water environment is affected by many factors, and it is usually not necessary to consider all of them. The commonly used COD measure was used to characterize the quality of the water environment in this study. According to China's surface water environmental quality standards (COD capacities of Class I and Class II water $\leq 15 \mathrm{mg} / \mathrm{L}$ ) [42] and the total available water resources in XNA, the total capacity of its water environment was 2,340 tons.

According to public information [43], in 2017, COD emissions by Beijing's primary industry amounted to 8799 tons. Combined with the GDP of the primary industry, its intensity of COD emissions was calculated at 73.08 tons/100 million yuan. The COD emission of the secondary industry was 2232 tons, and the intensity of its emissions was 0.42 tons/100 million yuan. In urban areas, 70,312 tons of COD was emitted at an intensity of 32.4 tons per 10,000 people.
Similarly, we assume that the intensities of COD emissions would not change given the same technical conditions.

Because the treated sewage usually enters natural water, the total amount of COD entering natural water could not exceed the capacity of the water environment. COD emissions from production and living are shown as

$$
\mathrm{ttlCOD}=\mathrm{GD} P_{\mathrm{pri}} * 73.08+\mathrm{GD} P_{\mathrm{sec}} * 0.42+\text { pop } * 32.40 \text {. }
$$

$t t l C O D$ is the total COD emissions from production and living, $G D P_{p r i}$ and $G D P_{s e c}$ are GDP of the primary and secondary industries, respectively, and $p o p$ is the total population. To maintain the quality of the water environment, the total COD emission $t t l C O D$ cannot exceed the total capacity of the water environment.

4.5. Land Demand Module. Because China has not described the detailed industrial land use of each city, this study refers to the national industrial land intensity as a measure (discussed later). According to the Statistical Yearbook of Urban Construction in China 2017, its urban population in that year was 813.47 million, and the area of land used for urban construction was $55,155.47 \mathrm{~km}^{2}$, including $11,083.70 \mathrm{~km}^{2}$ of industrial land, $5508 \mathrm{~km}^{2}$ occupied by commercial services, logistics and warehousing, and other tertiary industries, $16,979.27 \mathrm{~km}^{2}$ of residential land, and $21,584.5 \mathrm{~km}^{2}$ of other lands (land for public management and services, road and traffic facilities, general facilities, and green squares, accounting for $39.1 \%$ ). In 2017, China's industrial and tertiary industry GDP values were 27,999.69 billion yuan and $42,703.15$ billion yuan, respectively. The intensities of use of various types of construction land were obtained from this: the intensity of use of industrial land was $0.0396 \mathrm{~km}^{2} / 100$ million yuan, that of land for tertiary industry was 0.0129 $\mathrm{km}^{2} / 100$ million yuan, and that of residential land was $0.2087 \mathrm{~km}^{2} / 10,000$ people. Based on this, the increase in the land used for construction corresponding to the industry and population growth in XNA was calculated:

$$
\begin{aligned}
\text { Land }_{c}= & \mathrm{GDP}_{s} * 0.0396+\mathrm{GD} P_{t} * 0.0129 \\
& +\mathrm{Urba}_{\mathrm{pop}} * 0.2087+\text { lan } d_{\mathrm{other}},
\end{aligned}
$$

where $L a n d_{c}$ is the total land used for construction, $G D P_{S}$ and $G D P_{t}$ are the GDP values of the secondary and tertiary industries, respectively, Urban ${ }_{p o p}$ is the urban population, and land $d_{\text {other }}$ represents other types of land. Residential and industrial land continues to grow, but the total area cannot exceed the total planned area for construction. According to the planning outline of XNA, the intensity of its long-term development is controlled at $30 \%$ of land for construction, that is, $530 \mathrm{~km}^{2}$.

4.6. Atmospheric Environmental Capacity Module. The increase in industry and population usually leads to an increase in the volume of exhaust emissions. The atmospheric environmental capacity module calculates the social and economic carrying capacities of XNA based on the intensity 
of pollution emissions of its industries and population and its atmospheric environmental capacity. With the development of the new area, the use of motor vehicles will continue to increase, and emissions from them will become an important source of air pollution. The main pollutants from motor vehicles are nitrogen oxides [43]. Considering emissions from production, living, and motor vehicle emissions, we use nitrogen oxide content to evaluate the environmental atmospheric quality.

4.6.1. Atmospheric Environmental Capacity. The A-value method was used to measure the atmospheric environmental capacity. Based on the basic assumptions of the box model, it divides a given area into several functional areas and calculates the total allowable pollutant discharge according to the total area, the area of each functional partition, and the local total quantity control coefficient $A$ [44]. The formula is as follows:

$$
Q_{a k}=\sum_{i=1}^{n} Q_{a k i}=\sum_{i=1}^{n} A\left(C_{k i}-C_{0}\right) \frac{S_{i}}{\sqrt{S}} \text {. }
$$

$Q_{a k}$ is the total annual allowable discharge of $k$-th pollutant in the total control area, that is, the atmospheric environmental capacity, $Q_{a k i}$ is the annual allowable discharge of the $k$-th pollutant in the $i$-th functional zone, which is also the ideal air capacity, $C_{k i}$ is the annual average concentration limit of the $k$-th pollutant in the $i$-th functional area, $C_{0}$ is the background concentration value of the area, $S$ is the total area, $S_{i}$ is the city's $i$-th functional area, and $A$ is the control coefficient, which is mainly determined by the volume of local ventilation.

According to the above formula, the calculation of atmospheric capacity requires determining the local total volume control coefficient $A$. According to the Chinese national "Technical Methods for Establishing Local Air Pollutant Emission Standards (GB/T3840-91)," the cumulative probability of $A$ is 0.9 , and the $A$-value of each region is unified according to $A=A_{\text {min }}+0.1 \times\left(A_{\max }-A_{\min }\right)$. XNA is in Hebei Province, the $A$-value of which ranges from $4.2 \times$ $10^{4}$ to $5.6 \times 10^{4}\left(\mathrm{~km}^{2} / a\right)$. Based on this, the $A$-value of the XNA was determined to be $4.34 \times 10^{4} \mathrm{~km}^{2} / a$.

Using the total control coefficient, background concentration, and the area of each functional area, the total atmospheric environment capacity of the XNA was calculated to be 36,500 tons.

4.6.2. Air Pollution Emission. According to the 2017 Beijing Environmental Statistics Annual Report [43], Beijing emitted 144,514 tons of nitrogen oxides, mainly from industrial production, everyday living, and motor vehicles. In 2017 , the volume of emission of nitrogen oxides from the secondary industry in Beijing was 15,405 tons. Combined with the GDP, the intensity of emission of pollutants by the secondary industry was calculated to be 12.784 tons/billion yuan. Urban household nitrogen oxide emissions were 7510 tons, and their intensity of emission was 3.46 tons/10,000 people. Nitrogen oxide emissions from motor vehicles were
121,564 tons at an intensity of 205.73 tons/10,000 vehicles. The total nitrogen oxide emissions from production, living, and motor vehicles should not have exceeded the atmospheric capacity. The total nitrogen oxide emissions ( $t$ tlNO) were calculated as

$$
\mathrm{ttlNO}=\mathrm{GDP}_{\mathrm{sec}} * 127.84+\text { Pop } * 3.46+\text { Pop } * 0.27 * 205.73 .
$$

In the above, $G D P_{s e c}$ is the GDP of the secondary industry, Pop is its population, and 0.27 is the car ownership per capita. The values $127.84,3.46$, and 205.73 are, respectively, the intensities of industrial emission, emissions by the population, and those by motor vehicles.

4.7. Construction of XAM Model. The above modules were integrated to form the XAM, as shown in Figure 3. With the gradual transfer of industries, the population, GDP, and urbanization rate of XNA will change accordingly. The change in the industrial population will lead to changes in the total land for construction and water consumption as well as increases in COD emissions and nitrogen oxide emissions. This will affect the water environment and atmospheric environment. The process is a systematic one of element linkage.

\section{Scenario Setting and Results of Prediction}

By combining the developmental positioning of XNA and China's goal of modernization by 2035 , this study set three development scenarios to help determine the appropriate speeds and scales of transfer under different industrial transfer modes. With reference to the situation of some developed countries, that is, US, UK, Korea, Japan, Germany, and so on $[45,46]$, modernization requires that the tertiary industry account for more than $60 \%$ of all industry, the rate of urbanization be more than $75 \%$, and a high income (per capita GDP is higher than US\$12,235, equivalent to RMB 81,974.5, at the exchange rate in 2017: 1 US dollar is approximately RMB 6.7).

(1) Scenario 1. XNA will be just modernized in 2035; that is, the tertiary industry will just account for $60 \%$ of the total, the rate of urbanization will just reach $75 \%$, and the per capita GDP will be higher than 12,235 yuan.

The results of the XAM simulation (Table 1) show that, to achieve the above development goals, the rate of transfer of the secondary industry needed is 3.7 billion yuan per year and that of the tertiary industry is 6.4 billion yuan per year. At this speed, the tertiary industry will account for $60 \%$ of the total in 2035 , the urbanization rate will reach $75 \%$, and the per capita GDP will reach 83,900 yuan. By then, the GDP and population of the area will be 202.8 billion yuan and 2.416 million people, respectively, so the population will not exceed thelimitof the long-term development plan.

Under this development scenario, the construction land will not exceed the limit but the atmospheric environment will be 


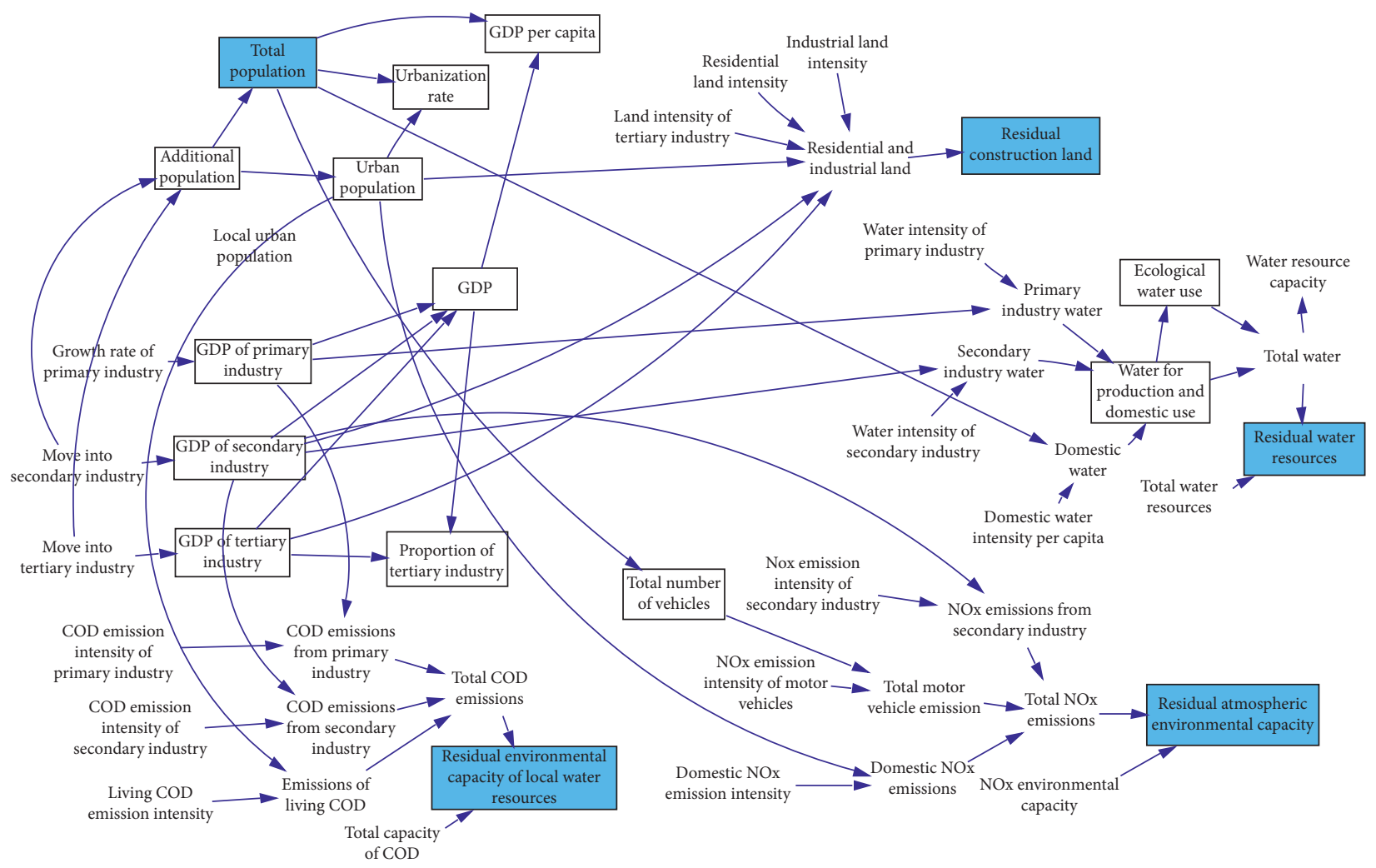

Figure 3: Xiong'an model (XAM).

TABLE 1: Simulation results by scenario.

\begin{tabular}{lccc}
\hline Industrial transfer scenario & Scenario 1 & Scenario 2 & Scenario 3 \\
\hline Transfer speed of second industry (billion yuan/year) & 3.7 & 1.5 & 1.9 \\
Transfer speed of tertiary industry (billion yuan/year) & 6.4 & 8.6 & 10.8 \\
Water resources & Overloaded & Overloaded & Overloaded \\
Water environment & Overloaded & Overloaded & Overloaded \\
Atmospheric environment & Overload in 2028 & Not overload & Not overloaded \\
Land resources & Not overloaded & Not overload & Not overloaded \\
GDP (billion yuan) & 202.8 & 202.8 & 249.6 \\
Population (10,000 persons) & 241.6 & 247.2 & 282.2 (beyond planned population) \\
Per capita GDP (million yuan/person) & 839 & 820 & 884 \\
Ratio of tertiary industry & $60 \%$ & $80 \%$ & $81 \%$ \\
Urbanization rate & $75 \%$ & $75 \%$ & $78 \%$ \\
\hline
\end{tabular}

Note. Water resources and the water environment carrying status are calculated based on local water resources (excluding inbound water resources).

overloaded by 2028. In addition, water resources were already overloaded in 2017, indicating that the original local water resources cannot support the local social economy. Therefore, the sustainable development of XNA requires the supply of inbound water. According to the 2017 Hebei Water Resources Bulletin, the inbound volume of water of Hebei Province was 3.545 billion $\mathrm{m}^{3}$. Owing to the inbound water supply, the following simulation no longer considers restrictions of water resources.

(2) Scenario 2. We achieve the goal of modernization by 2035 while ensuring that resources and the environment are not exhausted. We calculate the minimum speed of transfer as well as the corresponding scale economy and population.
The atmospheric capacity in scenario 1 was overloaded by 2028. Since the tertiary industry has less pollution emissions, this scenario requires increasing the speed of transfer of the tertiary industry until modernization is achieved in 2035 without exhausting resources and the environment. The results shown in Table 1 show that the minimum required transfer rate of the industry was 1.5 billion yuan per year for the secondary industry and 8.6 billion yuan for the tertiary industry. According to this rate, the ratio of the tertiary industry to the total will reach $80 \%$ in 2035 , the rate of urbanization will reach $75 \%$, and the per capita GDP will be 82,000 yuan. The total GDP and population will be 202.8 billion yuan and 2.472 million, 
respectively. The population will not exceed the limit on the population in the long-term plan. Compared with scenario 1, the per capita GDP has declined, because the tertiary industry is more labor intensive compared with the manufacturing.

(3) Scenario 3. On the basis of scenario 2, we expand the growth rate to find the maximum transfer rate that can be set as well as the corresponding economic and population-related scale without exhausting resources and the environment.

The results in Table 1 show that while ensuring that the resources and environment were not exhausted, the maximum transfer rates were 1.9 billion yuan per year for secondary production and 10.8 billion yuan per year for tertiary production. At this rate, the GDP and population in 2035 will be 249.6 billion yuan and 2.822 million, respectively, and the per capita GDP will reach 88400 yuan. The total population will exceed the planned population (2.5 million). Therefore, although this transfer model can achieve the largest population and economic scale without exhausting resources and the environment, it is limited by the planned population. These results provide an important reference to determine whether the planned population needs to be adjusted according to the industrial transfer mode.

In summary, the planned construction land in XNA is relatively rich in resources and can meet the needs of future development. The local water resources are relatively scarce and are insufficient to support the demand for water for industrial growth. However, inbound water resources are available. Development will be limited by the supply of inbound water resources, and the atmospheric environment will become an important limiting factor. To increase the carrying capacity of the atmosphere of XNA, it is necessary to increase the transfer ratio of tertiary industry. However, the tertiary industry has a greater demand for human resources. Increasing the volume of transfer of the tertiary industry also increases the total population. A larger scale of the economy and population transfer can be pursued while maintaining a healthy ecosystem but will be limited by the planned population. The results here can provide an important basis for industrial transfer and population planning.

\section{Discussion}

6.1. Validity and Usefulness of the Model. There are many other factors affecting the accuracy of the model. Among them, the industrial scale is an important factor that affects the effects of the industry on resources and the environment. In particular, the relation between industry and land use is complex, and the growth in the industrial scale is not linear with the demand for land use. Technological progress is another important factor that affects the intensity of resource consumption and pollution emission. However, the impact of technology is difficult to quantify, and in a short time, it is reasonable to assume that the technical level remains the same.
Even with all these possible uncertainties, the XAM can still help decision-making in this context. The results simulated by the XAM do not exactly represent the situation in the future but provide a tool to compare different scenarios and provide a basis for decisions on the developmental planning of new areas. The relative values of the model's predictions are more meaningful than their absolute values.

6.2. Model Optimization and Improvement. The industrial transfer is not determined unilaterally. The transfer of industries in Beijing will be restricted by its industrial planning. According to the "Outline of the Beijing-Tianjin-Hebei Coordinated Development Plan," Beijing's development is positioned as a "political center, a cultural center, a center for international exchanges, and a center for scientific and technological innovation." What needs to be addressed is the "noncore function of the capital," that is, the industries needing to be transferred. Therefore, the accurate differentiation of noncore functions in combination with Beijing's developmental positioning on the basis of further industrial segmentation should be examined in future work. In addition, this model focused only on the three common elements of water, soil, and the atmosphere as resource-related and environmental factors. In the future, more elements can be included, such as biodiversity and the soil environment.

6.3. Policy Implications. Economic growth normally follows an exponential law. This research focused on the BeijingXNA industrial transfer by setting a fixed speed of industrial transfer. In practice, the speed of industrial transfer is usually not constant. Compared with the speed of industrial transfer, the upper limit of the scale of transfer under various transfer modes is insurmountable. It is the ceiling set by local resources and the environment for industrial development and provides an important reference for decision-making.

\section{Conclusions}

The XNA was set up to relieve Beijing of its noncapital core functions and promote the coordinated development of the Beijing-Tianjin-Hebei region. The new area's undertaking in terms of industry and population is limited by its resource and environmental carrying capacity. This study simulated and analyzed the speed and maximum scale of industrial transfer to the new area under different industrial transfer modes. The results indicate that the carrying capacity of original local water resources in XNA has been overloaded, and it currently relies on incoming water resources to support its social economy. In addition to water resources, the primary limiting factor is the atmospheric environment, whereas the land is relatively rich in resources. To improve the economic scale of XNA, it is necessary to strengthen the transfer of the tertiary industry, which is labor intensive and will lead to greater population transfer and increased motor vehicle ownership. Therefore, to reduce air pollution, it is necessary to optimize motor vehicle control policies. The results specifically showed the following: 
(i) To just achieve the goal of modernization by 2035 (the tertiary industry will just account for $60 \%$ of the total and the rate of urbanization will just reach $75 \%)$, the transfer rates of the secondary and the tertiary industries should be 3.7 billion yuan/year and 6.4 billion yuan/year, respectively; then, the GDP and population in 2035 will be 202.8 billion yuan and 2.416 million people, respectively. In this mode, the atmospheric environment will be overloaded by 2028 .

(ii) To achieve modernization by 2035 and avoid the overloading of the atmospheric environment, the minimum speeds of transfer of secondary and tertiary industries needed to be 1.5 billion yuan per year and 8.6 billion yuan per year, respectively, and the total size of the economy and the population in 2035 would then be 202.8 billion yuan and 2.472 million people, respectively.

(iii) To determine the highest speed of industrial transfer under the condition that resources and the environment are not overloaded, the rates of transfer of the secondary and tertiary industries should be 1.9 billion yuan per year and 10.8 billion yuan per year, respectively. Then, the economic scale and population will reach 249.6 billion yuan and 2.822 million people in 2035 , respectively. The population here exceeds the planned population. This shows that although this transfer mode can maximize the economic growth of XNA, it will be limited by the planned population.

Finally, we highlight several aspects of this research which need to be improved. First, this study analyzed industrial transfer based on three major industry classifications, but differences occur in the resource consumption and intensity of pollution emission of various sectors within the same industry. In the future, it is necessary to further divide these industries. Second, this paper focused on resource-related and environmental constraints of XNA without analyzing the impact of industrial transfer on Beijing. Analyzing the impact of industrial transfer on Beijing's economy and population in combination with its industrial development and controlled planning is another area that needs to be explored.

\section{Data Availability}

The data used to support the results of this study come from various publicly published statistical yearbooks, which are described in detail in the article. A request for access to these data can be made to the corresponding author.

\section{Conflicts of Interest}

The authors declare that there are no conflicts of interest.

\section{Acknowledgments}

We are grateful to the two anonymous referees for their constructive comments and suggestions on the earlier versions of the paper. This study was supported by the Strategic Priority Research Program of the Chinese Academy of Sciences (Grant no. XDA19040401) and the National Natural Science Foundation of China (Grant no. 42071153).

\section{References}

[1] L. Zhou, X. Dang, Q. Sun, and S. Wang, "Multi-scenario simulation of urban land change in shanghai by random forest and CA-Markov model," Sustainable Cities and Society, vol. 55, pp. 1-10, 2020.

[2] S. Su, Z. Jiang, Q. Zhang, and Y. Zhang, "Transformation of agricultural landscapes under rapid urbanization: a threat to sustainability in hang-jia-hu region, China," Applied Geography, vol. 31, no. 2, pp. 439-449, 2011.

[3] T. N. Chase, R. A. Pielke, T. G. F. Kittel, R. R. Nemani, and S. W. Running, "Simulated impacts of historical land cover changes on global climate in northern winter," Climate Dynamics, vol. 16, no. 2-3, pp. 93-105, 2000.

[4] C. Weber and A. Puissant, "Urbanization pressure and modeling of urban growth: example of the tunis metropolitan area," Remote Sensing of Environment, vol. 86, no. 3, pp. 341-352, 2003.

[5] S. Yao, P. Zhang, C. Yu, G. Li, and C. Wang, "The theory and practice of new urbanization in china," Scientia Geographica Sinica, vol. 34, no. 6, pp. 641-647, 2014, in Chinese.

[6] F. Niu, X. Yang, and X. Zhang, "Application of an evaluation method of resource and environment carrying capacity in the adjustment of industrial structure in tibet," Journal of Geographical Sciences, vol. 30, no. 2, pp. 319-332, 2020.

[7] E. Pasqualini and M. Witkowski, "System dynamics approach for critical infrastructure and decision support: a model for a potable water system," Human Reproduction, vol. 25, no. 3, pp. 799-804, 2010.

[8] G.-E. Shim, S.-M. Rhee, K.-H. Ahn, and S.-B. Chung, "The relationship between the characteristics of transportation energy consumption and urban form," The Annals of Regional Science, vol. 40, no. 2, pp. 351-367, 2006.

[9] V. Henderson and A. Mitra, "The new urban landscape: developers and edge cities," Regional Science and Urban Economics, vol. 26, no. 6, pp. 613-643, 1996.

[10] R. Biles, "Thinking the unthinkable about our cities," Journal of Urban History, vol. 25, no. 1, pp. 57-74, 1998.

[11] C. Fang, S. Wang, and Y. Wang, "Current situation and countermeasures of Chinese low-carbon eco-metro area development," Geographical Research, vol. 35, no. 9, pp. 16011614, 2016, in Chinese.

[12] Y. Cao, "The hidden worries of the construction of state-level new areas," Decision-Making, vol. 12, pp. 56-58, 2014, in Chinese.

[13] J. Xie, "Population decentralization of the megalopolis in China," Urban Problems, vol. 3, no. 12-15, 1992, in Chinese.

[14] Y. Shi and D. Liu, "Excessive urbanization and rejuvenation in the metropolitan city center in shanghai, China," Journal of Urban Planning and Development, vol. 144, no. 4, pp. 1-11, 2018.

[15] W. Xu, Z. Zeng, Z. Xu et al., "Public health benefits of optimizing urban industrial land layout - the case of Changsha, China," Environmental Pollution, vol. 263, pp. 1-10, 2020.

[16] H. Meng, "Study on the present situation, problems and solutions of medical decentralization in central city of Beijing," Capital University of Economics and Business, vol. 3, pp. 19-27, 2014, in Chinese. 
[17] P. Zhao and S. Li, "Suburbanization, land use of TOD and lifestyle mobility in the suburbs: an examination of passengers' choice to live, shop and entertain in the metro station areas of Beijing," Journal of Transport \& Land Use, vol. 11, no. 1, pp. 195-215, 2018.

[18] C. Zhao, J. Jensen, and B. Zhan, "A comparison of urban growth and their influencing factors of two border cities: laredo in the US and nuevo laredo in mexico," Applied Geography, vol. 79, pp. 223-234, 2017.

[19] X. Lin, Y. Wang, S. Wang, and D. Wang, "Spatial differences and driving forces of land urbanization in China," Journal of Geographical Sciences, vol. 25, no. 5, pp. 545-558, 2015.

[20] J. Liu, J. Zhan, and X. Deng, "Spatio-temporal patterns and driving forces of urban land expansion in China during the economic reform era," AMBIO: A Journal of the Human Environment, vol. 34, no. 6, pp. 450-455, 2005.

[21] K.-y. Wu and H. Zhang, "Land use dynamics, built-up land expansion patterns, and driving forces analysis of the fastgrowing hangzhou metropolitan area, eastern china (19782008)," Applied Geography, vol. 34, pp. 137-145, 2012.

[22] X. Shen and L. J. C. Ma, "Privatization of rural industry and de facto urbanization from below in southern Jiangsu, China," Geoforum, vol. 36, no. 6, pp. 761-777, 2005.

[23] Y. Li and D. Jia, "The spatial-temporal distribution, strategic positioning and policy characteristics of state-level new areas," Journal of Beijing Administrative College, vol. 3, no. 22-31, 2016, in Chinese.

[24] L. Li, "Development potential and future direction of national new areas-A GRNN approach," Economic Geography, vol. 2, pp. 92-99, 2015, in Chinese.

[25] W. Kuang, W. Chi, D. Lu, and Y. Dou, "A comparative analysis of megacity expansions in China and the U.S.: patterns, rates and driving forces," Landscape and Urban Planning, vol. 132, pp. 121-135, 2014.

[26] Q. Weng, "Land use change analysis in the zhujiang delta of china using satellite remote sensing, GIS and stochastic modelling," Journal of Environmental Management, vol. 64, no. 3, pp. 273-284, 2002.

[27] J. Luo and Y. H. D. Wei, "Modeling spatial variations of urban growth patterns in Chinese cities: the case of Nanjing," Landscape and Urban Planning, vol. 91, no. 2, pp. 51-64, 2009.

[28] J. Cheng and I. Masser, "Modelling urban growth patterns: a multiscale perspective," Environment and Planning A: Economy and Space, vol. 35, no. 4, pp. 679-704, 2003.

[29] J. N. Wang and C. P. Luo, "Management system of national new areas and domain status and strategic tropism," Reform, vol. 2012, no. 03, pp. 21-36, 2012, in Chinese.

[30] C. Liu, X. Li, and X. Hang, "Path toward city-industry integration in new urban development zones," Urban Planning Forum, vol. S1, pp. 104-109, 2012, in Chinese.

[31] Y. Ma and R. Xu, "Remote sensing monitoring and driving force analysis of urban expansion in Guangzhou City, China," Habitat International, vol. 34, no. 2, pp. 228-235, 2010.

[32] G. Meng and M. Liu, "Evaluation on the establishment of free trade zones in tianjin binhai new area," Acta Geographica Sinica, vol. 66, no. 2, pp. 223-234, 2011, in Chinese.

[33] R. Xing, J. Chen, and L. Tian, "Development heterogeneity and dynamic mechanism of state-level new area-a case study of Pudong new area of Shanghai and Jiangbei new area of Nanjing," Resources and Environment in the Yangtze Basin, vol. 25, no. 6, pp. 859-867, 2016, in Chinese.

[34] National Development and Reform Commission (Chief Editor), Report on the Development of State-Level New Areas, China Planning Press, Beijing, China, 2015, in Chinese.
[35] D. Chen and W. F. Kong, "Discussion on characteristics and problems of state-level new area," Bulletin of the Chinese Academy of Sciences, vol. 31, no. 1, pp. 118-125, 2016, in Chinese.

[36] R. Yang, B. Hou, F. Lu et al., "Preliminary analysis and promotion of water resources carrying capacity for Xiongan New Area," Water Resources and Hydropower Engineering, vol. 50, no. 10, pp. 1-9, 2019, in Chinese.

[37] J. A. Macedo, "Reference approach for policy optimization in system dynamics models," System Dynamics Review, vol. 5, no. 2, pp. 148-175, 1989.

[38] F. Castellacci, "Co-evolutionary growth: a system dynamics model," Economic Modelling, vol. 70, pp. 272-287, 2018.

[39] A. Macmillan, J. Connor, K. Witten, R. Kearns, D. Rees, and A. Woodward, "The societal costs and benefits of commuter bicycling: simulating the effects of specific policies using system dynamics modeling," Environmental Health Perspectives, vol. 122, no. 4, pp. 335-344, 2014.

[40] A. Y. Hoekstra, M. M. Mekonnen, A. K. Chapagain, R. E Mathews, and B. D Richter, "Global monthly water scarcity: blue water footprints versus blue water availability," PLoS ONE, vol. 7, no. 2, Article ID e32688, 2012.

[41] Y. Wada, L. P. H. van Beek, D. Viviroli, H. H. Dürr, R. Weingartner, and M. F. P. Bierkens, "Global monthly water stress: 2 . Water demand and severity of water stress," Water Resources Research, vol. 47, no. 7, Article ID W07518, 2011.

[42] Ministry of Ecology and Environment of the People's Republic of China, Environmental Quality Standards for Surface Water (GB 3838-2002), Ministry of Ecology and Environment of the People's Republic of China, Beijing, China, 2002, http:// kjs.mee.gov.cn/hjbhbz/bzwb/shjbh/shjzlbz/200206/ t20020601_66497.shtml in Chinese.

[43] Beijing Municipal Ecological Environment Bureau, Beijing 2017 Environmental Statistics Annual Report, Beijing Municipal Ecological Environment Bureau, Beijing, China, 2018, http://sthjj.beijing.gov.cn/bjhrb/xxgk/ywdt/zlkz/hjtj37/ 842547/index.html in Chinese.

[44] D. Xu, Y. Wang, and R. Zhu, "Atmospheric environmental capacity and urban atmospheric load in mainland China," Science China Earth Sciences, vol. 61, no. 1, pp. 33-46, 2018.

[45] World Bank. (2017). World Development Indicators: Structure of Output. http://wdi.worldbank.org/table/4.2. (Accessed in Jan., 2021).

[46] World Bank. (2019). World Development Indicators: Structure of Output, https://databank.worldbank.org/source/ population-estimates-and-projections. (Accessed in March., 2021). 